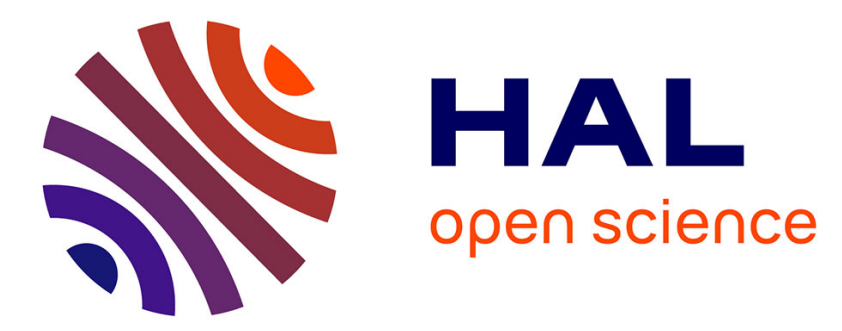

\title{
Fecal Calprotectin and Transferrin as Markers of Gut Inflammation in Children and Rat
}

Anne Breton, Rafael Garcia Villar, Jean-Pierre Olive, Jean Fioramonti, Lionel Bueno

\section{- To cite this version:}

Anne Breton, Rafael Garcia Villar, Jean-Pierre Olive, Jean Fioramonti, Lionel Bueno. Fecal Calprotectin and Transferrin as Markers of Gut Inflammation in Children and Rat. Digestive Disease Week / 102nd Annual AGA meeting, May 2001, Atlanta, Georgia, United States. 2001, Gastroenterology 120 (5 Suppl.1). hal-01600597

\section{HAL Id: hal-01600597 \\ https://hal.science/hal-01600597}

Submitted on 4 Jun 2020

HAL is a multi-disciplinary open access archive for the deposit and dissemination of scientific research documents, whether they are published or not. The documents may come from teaching and research institutions in France or abroad, or from public or private research centers.
L'archive ouverte pluridisciplinaire HAL, est destinée au dépôt et à la diffusion de documents scientifiques de niveau recherche, publiés ou non, émanant des établissements d'enseignement et de recherche français ou étrangers, des laboratoires publics ou privés.

\section{()(1)(2)}

Distributed under a Creative Commons Attribution - ShareAlikel 4.0 International 


$$
\begin{gathered}
\text { Gastronterology } 120 \text { (5 supl.1) DAW 2001- 102ad reeting of the AGA. } \\
\text { A.693 }
\end{gathered}
$$

significantly inhibits the inflammation in the LI induced by DSS treatment. Analysis of mRNA reveals that IL-18bp treatment can attenuate the upregulation of multiple pro-inflammatory cytokine genes, chemokines and matrix metalloproteinases (MMPs) in the large intestine that are commonly elevated during IBD.

\section{0}

Characterisation of Spontaneous Colltis in the mdr1a-deficient (mdr1a-/-) Mouse Kathy H. Banner, Pfizer Cent Research, Sandwich United Kingdom; Christophe Cattaneo, Jean-Loic Le Net, Pfizer, Amboise France; Alex Popovic, Jeremy D. Gale, Pfizer Cent Research, Sandwich United Kingdom

Panwala et al (J.Immunol, 1998; 161, 5733) reported how $25 \%$ of mdr1a-1- mice develop colonic inflammation, histologically similar to human IBD; we have also observed this. The aim of our study was to determine the suitability of the mdr $1 \mathrm{a}^{-1-}$ mouse for the identification of novel agents to treat human IBD. Specifically we have measured cytokines implicated in IBD and determined the sensitivity of these, together with the macroscopic, microscopic and clinical signs of colitis, to dexamethasone (dex, $0.05 \mathrm{mg} / \mathrm{kg}$ ip dally for 7 days). During a 3 week acclimatisation period $15 / 19 \mathrm{mdr}^{-1-} \mathrm{a}^{-1}$ mice developed clinical signs of colitis, including production of soft faeces and loss of body weight (bwt); control mice with the same genetic background did not. Mice were then assigned to 4 groups ( $n=5-10 /$ group). Colitis was scored using a composite index of clinical signs. 7 days later, the large intestine was removed for macroscopic and microscopic assessment. Levels of IL-8 and IFN- $y$ (pg/mg protein) were measured in homogenised colon by ELISA. Results are expressed as mean \pm sem. All mdr1a ${ }^{-1-}$ mice had microscopic evidence of inflammation in the caecum and colon, whilst FVB mice did not. Significant increases in the colon and caecum to bwt ratios (\%) and cytokine levels were seen in $\mathrm{mdr1}^{-1-}$ mice vs. FVB controls. Dex inhibited the increase in colon:bwt ratio, but had no effect on any of the other parameters measured. In conclusion, this study supports the similarity of the Gl inflammation present in this mouse with that of human IBD. The incidence of colitis was much higher than previously reported, with all mdr1 $1 \mathrm{a}^{-1-}$ mice having microscopic evidence of colitis. Prior to utilisation for the evaluation of novel therapeutic agents, it will be key to confirm that clinical symptoms and inflammation is responsive to a steroid.

\begin{tabular}{lllll}
\hline Groups & Colon:bwt \% & Caecum:bwt \% & IL-8 & IFN-y \\
\hline 1. FVB + water & $1.04 \pm 0.02$ & $0.60 \pm 0.06$ & $96 \pm 3$ & nd \\
2. FVB + dex & $1.10 \pm 0.04$ & $0.51 \pm 0.01$ & $177 \pm 52$ & $24 \pm 18$ \\
3. mdrla + water & $3.39 \pm 0.39 *$ & $0.85 \pm 0.06 *$ & $397 \pm 70 *$ & $253 \pm 52 *$ \\
4. mdr1a+ + dex & $2.78 \pm 0.27 * \dagger$ & $0.79 \pm 0.05 *$ & $617 \pm 128 *$ & $313 \pm 58 *$ \\
\hline
\end{tabular}

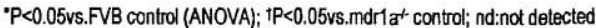

\section{1}

Fecal Calprotectin And Transferrin As Markers of Gut Inflammation In Children And Rat Anne Breton, CHU Purpan, Toulouse France; Rafael Garcia-Villar, INRA, Toulouse France; Anne Breton, CHU Purpan, Toulouse France; Rafael Garcia-Villar, INRA, Toulouse France;
Jean-Pierre Olive, CHU Purpan, Toulouse France; Jean Fioramonti, Lionel Bueno, INRA, Toulouse France

Daily care of children with inflammatory bowel disease (IBD) would benefit of a simple noninvasive marker of intestinal inflammation. A similar marker would be useful also in animal models of IBD. Recent studies point towards the neutrophil protein calprotectin as a reliable fecal marker of gut inflammation. In rats, transferrin rather than calprotectin appears as a relevant granulocyte marker protein. This study investigated whether calprotectin and transferrin could serve as fecal markers of gut inflammation in IBD children and rats with experimental enterocolitis. Methods: Fecal calprotectin and transferrin were assayed by ELISA. The human study involved 44 children: 11 Crohn's disease (CD), 11 ulcerative colitis (UC), 12 acute infectious diarrhea $(A D), 10$ controls. Disease intensity was evaluated by clinical ratings, biological and ultrasound data. The animal study involved 25 male Wistar rats in which enteritis (10 rats; $E$ group) or colitis ( 15 rats; $C$ group) was induced by intraluminal trinitrobenzene sulfonic acid (TNBS, 180 and $40 \mathrm{mg} / \mathrm{kg}$ resp.). Feces were collected daily from the day before until day 4 after TNBS when rats were sacrificed. Gut inflammation was then assessed by histology and myeloperoxidase (MPO) assay. Protein concentrations ( $\mu \mathrm{g} / \mathrm{g}$ feces) were expressed as means \pm SEM. Results: In children, fecal calprotectin was higher in $C D(2780$ $\pm 592 ; p<0.05)$, UC $(6028 \pm 1711 ; p<0.01)$ and $A D(1394 \pm 771 ; p<0.01)$ than in controls $(26.4 \pm 6.0)$. Fecal transferrin was higher in UC $(131 \pm 43 ; p<0.001)$ and $A D(50 \pm 28$; $p<0.01)$, but not $C D(12.2 \pm 5.3 ; p>0.05)$, than in controls $(0.17 \pm 0.04)$. Fecal calprotectin was correlated to fecal transferrin in UC $(r=0.88 ; p<0.0001)$ and $A D(r=0.68 ; p<0.0001)$, but not $C D(r=0.19 ; p>0.05)$. Fecal calprotectin was correlated to the severity of $C D$ $(p<0.01)$ and $U C(p<0.001)$, whereas fecal transferrin was correlated only to that of UC $(p<0.001)$. In rats, we could not determine fecal calprotectin. In contrast, fecal transferrin that was $19.7 \pm 4.2(E)$ and $25.6 \pm 5.6(C)$ in control conditions $(p>0.05)$, increased from day 1 post-TNBS $(1250 \pm 353, E ; 7414 \pm 2403, C)$ and remained high by day $4(6369 \pm$ $2017, E ; 3608 \pm 950, C)$ ( $p<0.01$ vs resp. controls). Fecal transferrin and tissue MPO were correlated in colitis $(r=0.64 ; p<0.01)$ but not enteritis $(r=0.45 ; p>0.05)$. Conclusion: Fecal calprotectin appears more suited than fecal transferrin to assess gut inflammation in IBD children. In rats, however, fecal transferrin seems to be a relevant marker of inflammation at least in a model of TNBS-induced colitis.
3742

Nitric Oxide Modulates Th1 Inflammatory Response in Experimental Collits Meritxell Gironella, Azucena Salas, Felix Gill, Antonio Soriano, Miquel Sans, Josep M. Pique, Julian Panes, Hosp Clin, Barcelona Spain

Background \& Aims: Chronic administration of a nitric oxide donor, DETANO, improves the clinical symptoms of DSS-induced colitis in mice. This model of colitis is characterized by an activation of $T$ cells with a Th1 phenotype where IL-12 plays a critical role. Furthermore, NO has been shown to down-regulate IL-12 synthesis by macrophages in vitro. Therefore, the aim of this study was to analyze the molecular mechanisms involved in the regulation of the inflammatory response by NO in experimental DSS-induced colitis. Methods: Colitis was induced in mice by giving 5\% DSS in drinking water for 4 days. A group of mice was treated daily with $1 \mathrm{mg} / \mathrm{kg} /$ day DETANO s.c. and the control group with PBS. Loss of body weight was determined daily until day 7 when colon weight and myeloperoxidase activity were assessed. IL-12 protein expression was analyzed by Western-blot and its mRNA expression by RT-PCR. Moreover, levels of IFN-y mRNA were also analyzed. Results: Administration of DETANO significantly attenuated colonic disease inflammatory signs, such as body weight loss $(7.8 \pm 2.2$ vs $1.1 \pm 1.9)$, colon weight $(320 \pm 11$ vs $275 \pm 8)$ and MPO activity $(2.03 \pm 0.6$ vs $1.0 \pm 0.15)$. Levels of $\mathrm{IL}-12$ protein increased $(270 \pm 49 \%)$ in colitic animals in comparison with controls in the same way as its mRNA $(45 \pm 1.7 \%)$. Also, a significant increase in IFN$\gamma$ mRNA levels was detected $(122.5 \pm 12 \%)$. The severity of colitis, determined as body weight loss at day 7 , had a positive correlation with IL-12 mRNA levels $(r=0.88, p<0.02)$, which also positively correlated with IFN- $\gamma$ mRNA levels $(r=0.93, p<0.01)$. Treatment of colitic mice with DETA-NO significantly $(p<0.05)$ decreased IL-12 protein and mRNA to levels similar to those of control animals. This down-regulation of IL-12 was associated with a significant reduction ( $p<0.02$ ) of IFN-y mRNA levels. Conclusions: Nitric oxide has an anti-inflammatory effect in DSS-induced experimental colitis by decreasing intestinal synthesis of IL-12 and IFN- $y$. These effects may be the basis for the therapeutic benefit of DETANO on experimental colitis in mice.

\section{3}

Inhibition of DSS-Induced Colitis by TZO Ligands for PPAR y 1 Dependent on TLymphocyles.

Anne Flanigan, Hahnemann Univ Sch of Medicine, Philadelphia, PA; Thomas A. Judge, Sue A. Keilbaugh, Univ of Pennsylvania Sch of Medicine, Philadelphia, PA; R Arifaddin, Sreekant Murthy, Hahnemann Univ Sch of Medicine, Philadelphia, PA; Gary D. Wu, Univ of Pennsylvania Sch of Medicine, Philadelphia, PA

INTRODUCTION: Peroxisome proliferator-activated receptor $\gamma(\mathrm{PPAR} \gamma)$ is a member of the nuclear hormone receptor superfamily whose ligands include a new class of oral antidiabetic agents, the thiazolldinediones (TZDs). PPARyligands are best characterized as regulators of adipocyte differentiation and glucose homeostasis. However, emerging evidence suggests that TZD exhibit immune modulatory functions both in vitro and in vivo. In this regard, we have previously shown that $\mathrm{ZZO}$ s dramatically reduce inflammation in DSS-induced murine colitis. PPARyis expressed in multiple epithelial and myeloid lineage cell types. The specific colitis. PPARyis expressed in multiple epithis study was to determine the cellular target for the TZD regulated effect on DSSaim of this study was to determine the cellular target for the TZD regulated effect on DSSwere treated with $3 \%$ DSS in drinking water to induce colitis. Subsequently, mice were gavaged daily with either BRL49653 (20 mg/kg/day) or vehicle for eight days during which time a disease activity index (DAI) was ascertained. At the termination of the study, colonic tissue was harvested for histologic and gene expression analysis. In order to identify which myeloid cell lineages express PPAR $y$, splenic and peripheral node leukocytes from D011.10 transgenic mice were analyzed by flow cytometry. RESULTS: Both SCID and RAG-1- mice were relatively resistant to DSS-induced colitis. Furthermore, the DAI decreased more rapidly once DSS administration was discontinued than wt mice of the same strain. BRL49653 treated animals did not show any improvement in colitis compared to vehicle treated controls. Flow cytometry experiments demonstrated that significant levels of PPARyare expressed in CD45Rbhi and lo T lymphocytes, macrophages, but not B lymphocytes or NK cells. Furthermore, we show that PPARyexpression is maintained in T- lymphocytes following stimulation with nominal peptide in the presence or absence of IL-12. Conclusions: These results suggest that $\mathrm{T}$ and/or B Lymphocytes accelerate the onset and inhibit the resolution of colitis in mice treated with DSS. Furthermore, BRL49653 likely exerts its anti-inflammatory effect through a T lymphocyte dependent mechanism since neither SCID nor RAG - I- mice demonstrated any therapeutic effect with the administration of this TZD and PPARyis expressed in T but not B lymphocytes.

\section{4}

Essential Role of Macrophage Migration Inhibitory Factor (MIF) In The Pathogenesis Of Dextran Sulfate Sodium-Induced Colitis In Mice: Amelioratlon OI Colocecal Damage By Anti-MIF Antibody

Tatsuya Ohkawara, Hiroshi Takeda, Jun Nishihira, Masatoshi Takano, Hidetoshi Kagaya, Kaku Hokari, Hokkaido Univ Graduate Sch of Medicine, Sapporo Japan; Toshihiko Iwanaga, Hokkaido Univ Graduate Sch of Veterinary Medicine, Sapporo Japan; Mototsugu Kato, Toshiro Sugiyama, Masahiro Asaka, Hokkaido Univ Graduate Sch of Medicine, Sapporo Japan

Background \& Aims: During the past decade, macrophage migration inhibitory factor (MIF) has been reevaluated as a protein involved in broad-spectrum pathophysiological states as an inflammatory cytokine, pituitary-derived hormone, and glucocorticoid-induced immunomodulator. In this study, we investigated the potential role of MIF in the pathogenesis of inflammatory bowel disease (IBD) using dextran sulfate sodium (DSS)-induced colitis in mice. Methods: To induce colitis, BALB/C mice were fed $4 \%$ DSS in their drinking water continuously for up to 7 days. The severity of colitis was assessed by body weight, rectal bleeding, diarrhea, colon length, and histological analysis. Both MIF protein and MIF mRNA expression in the colocecal tissues were examined by immunohistochemistry and Northern blot analysis, respectively. To assess the effect anti-MIF antibody on the DSS-colitis, an anti-MIF polyclonal 